Volume 8, No.6, November - December 2019

International Journal of Advanced Trends in Computer Science and Engineering

Available Online at http://www.warse.org/IJATCSE/static/pdf/file/ijatcse76862019.pdf

https://doi.org/10.30534/ijatcse/2019/76862019

\title{
The Development of Engine Control Module Manipulator Module Based on Arduino to Increase Power and Torque of Motorcycle Engine
}

\author{
Supriyono ${ }^{1}$, Iman Mawardi ${ }^{2}$, Waluyo Adi Siswanto ${ }^{3}$ \\ ${ }^{1}$ Faculty of Engineering, Universitas Muhammadiyah Surakarta, Surakarta, Indonesia \\ supriyono@ums.ac.id \\ ${ }^{2}$ Faculty of Engineering, Universitas Muhammadiyah Surakarta, Surakarta, Indonesia \\ ${ }^{3}$ Faculty of Engineering, Universitas Muhammadiyah Surakarta, Surakarta, Indonesia
}

\section{ABSTRACT}

The aim of this research is to develop an Engine Control Module (ECM) manipulator module of motorcycle engine, to produce higher power and torque than standard one. An Oxygen sensor of narrow band type was used to detect the oxygen in the exhaust manifold. The narrow band type of oxygen sensor is used to maintain the air fuel ratio (AFR) at certain number closed to stoichiometry condition. The manipulator was located in between oxygen sensor and ECM. The manipulator is made based on Arduino Nano microcontroller. Two source codes were developed. The first source code maintained the combustion in richer condition (manipulator I). The second source code maintained the combustion in weaker condition (manipulator II). The power and torque parameters of the test engine was evaluated by using the dynamometer test. The emission test was carried out to evaluate the emission's level. The results showed that the manipulators developed in this work increased the power and torque of the test engine. By applying the manipulators the ECM maintains the AFR at the value of 14.2:1. An ECM manipulator module based on Arduino was successfully developed in this work. The rise of the power and the torque was due to the rise number of the fuel injected to the combustion chamber as indicated by the rise of the $\mathrm{CO}$ and HC. The emission levels were still under the allowable values.

Key words : Engine Control Module, Arduino, Motorcycle Engine, Arduino Micro Controller.

\section{INTRODUCTION}

Engine management system (EMS) is an electronic control system. According to CHEN et al. [1] electronic control system enables automotive technology to meet the demands of fuel economy, emission levels, improvements in the dynamics and safety of vehicles. The components that make up the EMS are electronic components such as sensors, relays, actuators and Engine Control Modules (ECM). These components work together to control all functions of the engine effectively. ECM which is a major part of EMS is a computer (microchip) for processing input from various sensors in real-time. ECM consists of hardware and software.

The hardware is a printed circuit board (PCB) on which a chip (microcontroller) is mounted. Meanwhile, the software is installed into the microcontroller. It is therefore possible to replace the ECM by updating the software or by replacing the chip as needed. Currently, ECM is available as a spare part that is ready to use. But their existence is not an open platform so it is almost impossible to get access to develop it. Moreover, in terms of price, it is still very expensive.

Research on electronic control of engines has been conducted since the late 1970s. The beginning of this research was based on the need to save fuel, improve performance and reduce emission levels. As a system, electronic engine control is a complex that consists of many sub-control modules. The factor that determines engine performance from the fuel consumption and emission levels indicator point of view is the ratio of air fuel mixture (air fuel ratio or AFR) [1,2].

By improper AFR settings, engine performance and fuel efficiency will decrease and at the same time exhaust emissions will increase. In this case the mixture of air and fuel needs to be made so that it meets the optimal AFR value which is around 15:1. All modern automotive engines currently are controlled by ECM.

In petroleum engines that use electronic fuel injection (often known as EFI), the AFR control strategy is based on steady state conditions [3]. This method ignores several factors, i.e.: vacuum fluctuations of the intake air mass, the effect of wetting the combustion chamber walls by the fuel and the effect of time delays in transient states [4]. This will lead to low control accuracy [5]. However, the development of control theory and current sensor technology, an accurate AFR control is achievable. As research by Yildiz, et al. [6], the average AFR value that combines steady state and transient conditions is proposed. This is based on observing the actual work process of a four-step engine. 
Furthermore, the research by Wang, et al. [7], is a predictive model of AFR control. It is based on a neural network model used to handle non-linear systems and uncertain parameters. Using multispeed sampling technique $\mathrm{He}$, et al. [8], made an engine model and planned a sensor to control AFR based on injected fuel and exhaust gas dynamics. Then A. Cavina et al. [9] introduced a closed loop AFR control design using a spectrum of oxygen sensor signals. The oxygen sensor detects the oxygen content of the exhaust gas which is then used to control fuel injection so that the AFR is always on the desired value.

Today, almost all motorcycle manufacturers in Indonesia already use EMS on their products. The ECM used is set to maintain AFR at the value that are close to stoichiometry conditions. Theoretically, the ideal value of AFR is around 15: 1, however the ideal AFR value does not mean that it produces the maximum power and torque. The maximum power is obtained from lower AFR which is around 12.6:1. This research will develop an ECM manipulator module for motorcycle engine to produce higher power and torque than the standard one for certain AFR value. The module will be built based on an Arduino microcontroller.

Arduino is an open source platform. It makes easy for practitioners, academics or anyone who wants to learn about electronics and programming to design various interactive objects that can communicate with us and the environment. This is in accordance with the report made by Recktenwald and Hall [10] about the use of Arduino as a platform for programming, design, and measurement in engineering classes. Furthermore Barber et al. [11], used Arduino as a cheap hardware, to connect Simulink with the control system tools of the Bachelor Control Engineering course at Carlos III University of Madrid. At that time, the control system control tool was connected to the computer via an expensive Data Acquisition Card.

The experience of using Arduino for experiments in the Automatic Control and Robotics laboratory was carried out by Candelas, et al. [12] at the University of Alicante, Spain. The conclusion was that the practicum attracted the interest of students and students gained knowledge about hardware configuration and programming. Alsmadi, et al. [13] used Arduino for automatic control of a vehicle's safety device to prevent collisions. Based on the measurement of the distance of the vehicle with an object in front of it, the vehicle's safety device will provide a warning to the driver in several ways. Arduino-based security devices to locate and switch off stolen vehicles were made by Kiruthikamani, et al. [14]. This device is very reliable, inexpensive and friendly. It can help immediately find a stolen vehicle.

Another example of the use of Arduino in automation and control is the creation of double robot arms for transportation of material in a production line by Chen, et al. [15]. To the best of Author's knowledge, there have been very limited reports on the application of Arduino in the control engine. Taking into account the potential of Arduino and electronic control engine, this work will develop the application of Arduino in the electronic control engine.

\section{EXPERIMENTS}

The testing engine is a Honda PGM-FI eSP with cylinder capacity of $108.2 \mathrm{cc}$ and the compression ratio of 9.5:1. An oxygen sensor of narrow band type is used to detect the oxygen content in the exhaust manifold. The voltage of narrow band type of oxygen sensor changes with the change in AFR as shown in Figure 1, followed from reference [16]. These voltage changes were used by ECM to control the duration of fuel injection to maintain the AFR in certain number

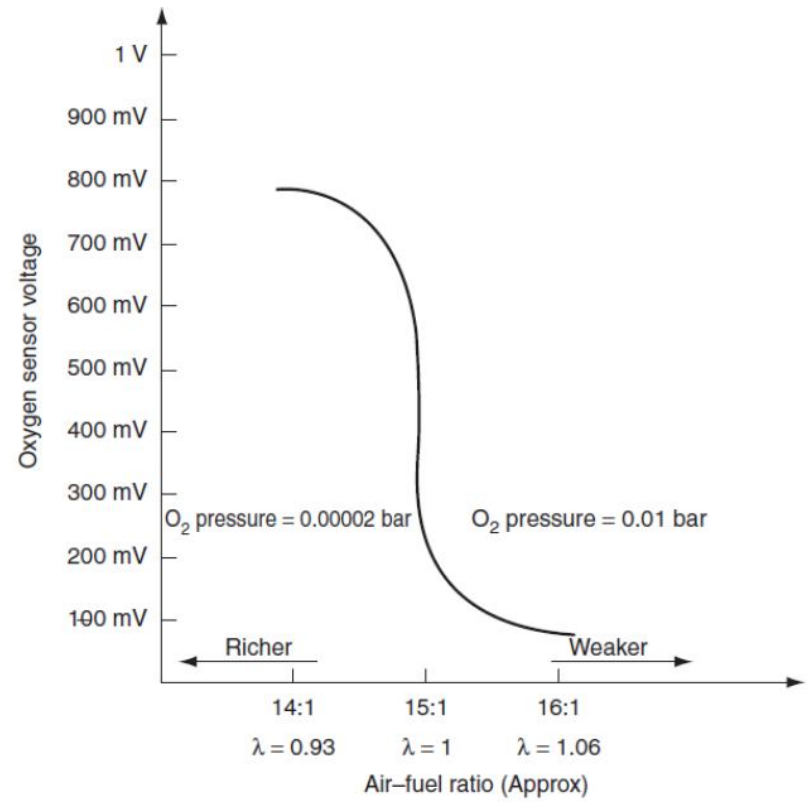

Figure 1: Change in sensor voltage as air-fuel ratio changes.

The manipulator developed in this work is positioned in between oxygen sensor and ECM. The original voltage from the oxygen sensor was manipulated by the manipulator and transferred into ECM. Based on Figure 1 above, two strategies of manipulation were selected. The first was to maintain the combustion on richer condition and the second was to maintain the combustion in weaker condition. For the purposes of programming, the two strategies were translated into following algorithms:

1. If the oxygen sensor voltage is less than 0.4 volts, the manipulator gives a voltage of 0.45 volts to the ECM else the manipulator gives a voltage of 0.8 volts to ECM.

2. If the oxygen sensor voltage is more than 0.4 volts, the manipulator gives a voltage of 0.45 volts to the ECM else the manipulator gives a voltage of 0.2 volts to ECM. 
Two source codes were built based on the two algorithms by using $\mathrm{C}$ programming language and are installed into Arduino Nano microcontrollers to be the manipulators. In this case, two manipulators were produced. The first manipulator (Manipulator I) was for the first algorithm and the second manipulator (Manipulator II) was for the second algorithm. Evaluation of each manipulator was conducted on project board to ensure that it works correctly.

The evaluation was carried out in accordance with a wiring diagram as shown in Figure 2. A potentiometer was used instead of an oxygen sensor. The potentiometer was set to give voltage of A0 pin of the Arduino from 0.2 volts to 0.8 volts. The output voltage of D9 pin was then measured to ensure a correct voltage as in algorithms.

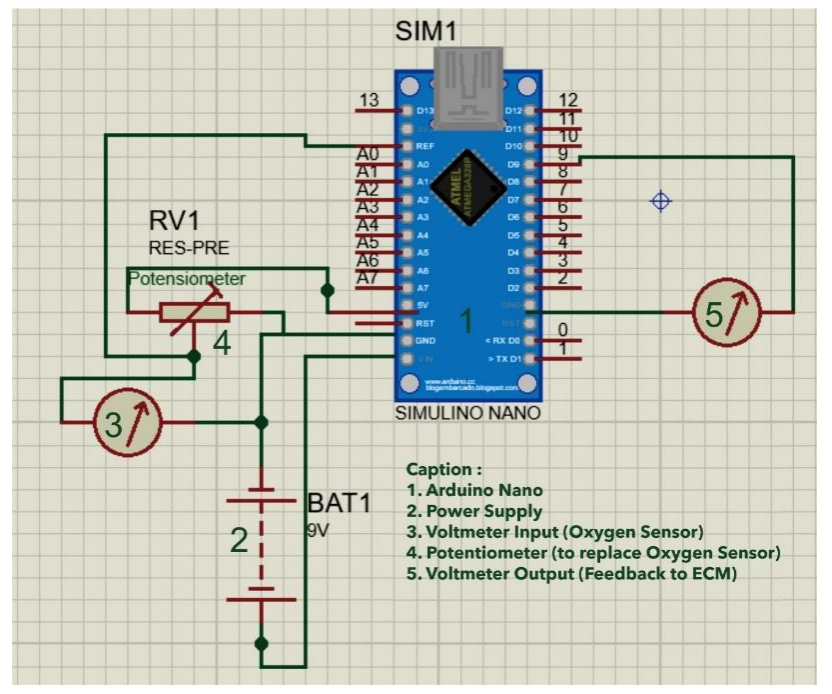

Figure 2: Wiring diagram of the manipulator evaluation.

Once the manipulators are working properly, the next step is installation the two manipulators on the motorcycle. The installation on the motorcycle is illustrated in Figure 3

After completing the installation, dynamometer and emission tests are carried out. The dynamometer tests are conducted on Sportdyno V3.5 to have power and torque for any engine rotation, while the emission tests are conducted on Heshbon automotive emission analyzer HG-520 to ensure that the emissions are on the allowable levels. The dynamometer and emission tests are performed on a standard motorcycle, the one with first manipulator and, the one with second manipulator.

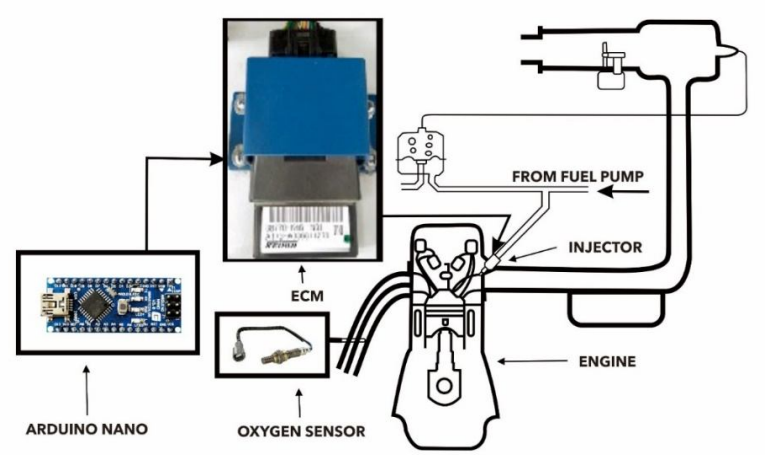

Figure 3: Illustration of installation on motorcycle.

\section{RESULTS AND DISCUSSION}

The results of the dynamometer test for powers and torques are presented in Figure 4 and Figure 5 respectively, while the emission test results are shown in Table 1.

Table 1: Emission test results.

\begin{tabular}{ccccc}
\hline Test item & $\begin{array}{c}\text { Standa } \\
\text { rd }\end{array}$ & $\begin{array}{c}\text { Manipulato } \\
\text { r I }\end{array}$ & $\begin{array}{c}\text { Manipulato } \\
\text { r II }\end{array}$ & Ideal \\
\hline AFR & $14.2: 1$ & $14.2: 1$ & $14.2: 1$ & $\begin{array}{c}14.7: \\
1\end{array}$ \\
$\mathbf{C O}(\%)$ & 0.42 & 0.57 & 0.54 & $<3.5$ \\
$\begin{array}{c}\text { HC } \\
(\mathbf{p p m})\end{array}$ & 128 & 156 & 165 & $<300$ \\
$\mathbf{C O 2}(\%)$ & 8.4 & 9.9 & 10.3 & $12-16$ \\
$\begin{array}{c}\text { LAMBD } \\
\mathbf{A}\end{array}$ & 0.970 & 0.967 & 0.969 & 1 \\
\hline
\end{tabular}

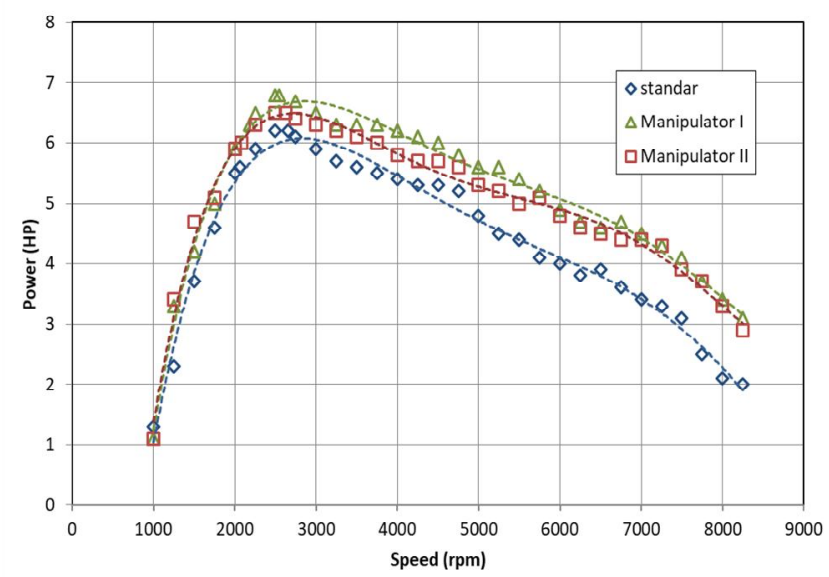

Figure 4: Result of dynamometer test in term of power. 


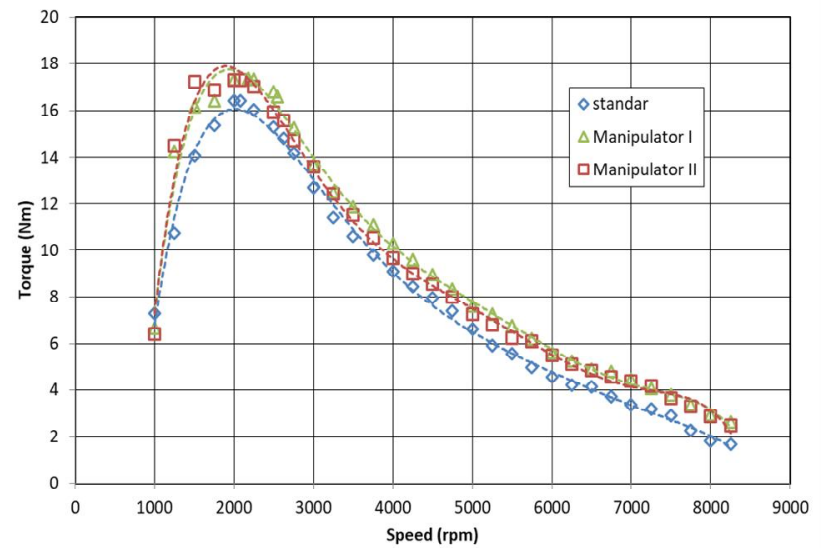

Figure 5: Result of dynamometer test in term of power.

It can be seen from Figure 4 and Figure 5 that the motorcycles with the manipulators have higher powers and torques than the standard motorcycle. The manipulator I increases the power and the torque more than the manipulator II does. It is for sure that the increase in engine powers and torques is a result of combustion changes in the combustion chamber. The changes are due to the response of the ECM to the application of the manipulators.

There are two possibilities of the ECM response. The first one is the ECM decrease the AFR to have more power and torque (as it can be seen in Figure 5) or the second one is the ECM asks more fuel injected to the combustion chamber. In this case, the second possibility is something that happened. This is confirmed by the results of exhaust emission tests as the ECM maintain the AFR at 14.2:1.

The results of the emission tests show that by applying the manipulators, the ECM maintains the AFR at the ratio of 14.2: 1. According to the work by Najjar et.al. [17], the use of the narrow band oxygen sensor is that it only measures lambda about the stoichiometric region without sensing how lean or rich the fuel mixture is. This is not the ideal ratio.

The chemical formula of gasoline is assumed as C8H18 [18]. The equilibrium reaction (stoichiometry) between fuel and oxygen is $\mathrm{C} 8 \mathrm{H} 18+12.5 \mathrm{O} 2=>8 \mathrm{CO} 2+9 \mathrm{H} 2 \mathrm{O}$. However, dry air contains $21 \% \mathrm{O} 2$ and $79 \% \mathrm{~N} 2$. On the other words for 1 mole oxygen in the dry air, there is 3.76 moles nitrogen. So, the stoichiometry reaction can be written as $\mathrm{C} 8 \mathrm{H} 18+(12.5)(\mathrm{O} 2$ $+3.76 \mathrm{~N} 2)=>8 \mathrm{CO} 2+9 \mathrm{H} 2 \mathrm{O}+3.76(12.5) \mathrm{N} 2$ or $\mathrm{C} 8 \mathrm{H} 18+$ $12.5 \mathrm{O} 2+47 \mathrm{~N} 2=8 \mathrm{CO} 2+9 \mathrm{H} 2 \mathrm{O}+47 \mathrm{~N} 2$. In term of mass, the stoichiometry reaction needs 400 grams of oxygen where at the same time 1316 grams of nitrogen get involve. Therefore, the ideal AFR can be calculated by using Eq. 1:

$$
\text { AFR }=\frac{\text { mags of a ir }}{\text { mass of gasoline }}=\frac{\varrho_{Z} \text { mass }+N_{Z} \text { mass }}{c_{M} H_{1} \text { mass }}
$$

$$
=\frac{400+1316}{114}=15.05
$$

AFR for stoichiometry conditions is 15 : 1 , which means it takes 15 grams of air to burn out 1 gram of gasoline (but the value that is often used in industry is 14.7). This stoichiometry AFR will produce complete combustion, known as lambda 1 . The complete combustion means the best emission levels, however it is not the best to produce power and torque (as it can be confirmed by Figure 6).

The use of the manipulators decrease slightly the value of the lambda of the standard motorcycle (see table 1). The lambda value of the standard motorcycle is 0.970 . The one with manipulator I is 0.967 and the one with manipulator II is 0.69. As per Figure 6, the decrease in lambda value increases the powers and the torques of the motorcycle. This is in accordance with the dynamometer tests where the manipulator I has the smallest lambda on the other hand it has the largest powers and torques.

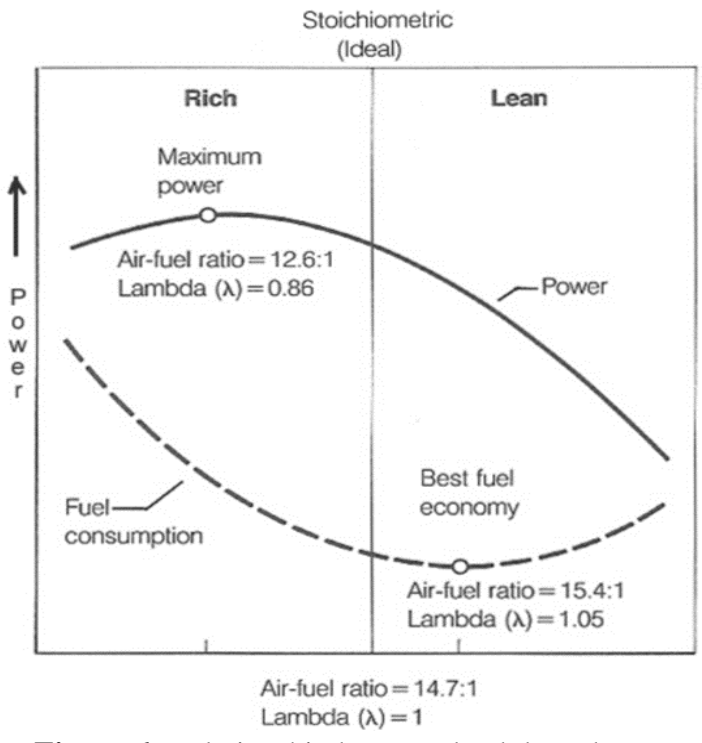

Figure 6: Relationship between lambda and power.

The decrease of the lambda is followed by the increase of $\mathrm{HC}$ content. The HC contents are 128 ppm, 156 ppm, and 165 ppm for the standard motorcycle, the motor with manipulator I and the motor with manipulator II respectively. The ups and downs of HC levels are produced by the amount of fuel supplied to the chamber. Poor mixture results in greater HC levels due to the slow combustion process that occurs so that the fuel will come out before the fuel burns completely [19].

The decrease of the lambda is also followed by the increase of the percentages of $\mathrm{CO}$ and $\mathrm{CO} 2$. The $\mathrm{CO}$ content will increase with the decrease of the lambda as the fuel-air mixture is richer. While the increase of the $\mathrm{CO} 2$ content indicates a better combustion. The emission test results show that the strategies of the manipulation in this research are working 
properly. The contents of $\mathrm{HC}, \mathrm{CO}$ and $\mathrm{CO} 2$ of the manipulator II show that the mixture of fuel-air is weaker than manipulator I.

\section{CONCLUSION}

A conclusion section is not required. Although a conclusion may review the main points of the paper, do not replicate the abstract as the conclusion. A conclusion might elaborate on the importance of the work or suggest applications and extensions.

\section{ACKNOWLEDGEMENT}

The authors would like to thank to Directorate of Research and Community Service, Directorate General of Research Strengthening and Development of the Indonesian Ministry of Technology and Higher Education with contract number 199.61/A.3-III/LPPM/V/2019 for the financial support to conduct this research.

\section{REFERENCES}

1. Hong, C., Xun, G., Yun-Feng, H. U., Qi-Fang, L., Bing-Zhao, G., \& Hong-Yan, G. (2013). Automotive control: the state of the art and perspective. Acta Automatica Sinica, 39(4), 322-346. https://doi.org/10.1016/S1874-1029(13)60033-6

2. Azanov, A.V., Amosov, A.G., Khlopkov, S.V., \& Khodyakov, A.A. (2019). Effects of tribotechnical composition, engine oil, and iso-octane on samples of elastomers of automobile technology in aviation industry, International Journal of Advanced Trends in Computer Science and Engineering, 8(5), 2236-2239. https://doi.org/10.30534/ijatcse/2019/58852019

3. Gonzalez, E. G., Florez, J. A., \& Arab, S. (2008). Development of the management strategies of the ECU for an internal combustion engine: computer simulation. Mechanical Systems and Signal Processing, 22(6), 1356-1373.

https://doi.org/10.1016/j.ymssp.2007.11.030

4. Cho, J.H., \& Ki, R.H.(2019). A case study in the design stage for hardware system performance enhancement of active electronic engine mount control. International Journal of Advanced Trends in Computer Science and Engineering, 8(4), 1504-1508 https://doi.org/10.30534/ijatcse/2019/72842019

5. Ganthia, B.P., Sahu, S.R., Biswal, S., Abhisekh, A., \& Barik, S.K. (2019). Genetic algorithm based direct torque control of vsi fed induction motor drive using matlab simulation. International Journal of Advanced Trends in Computer Science and Engineering, 8( 5), 2359-2369.

https://doi.org/10.30534/ijatcse/2019/76852019

6. Yildiz, Y., Annaswamy, A., Yanakiev, D., \& Kolmanovsky, I. (2008). Adaptive air fuel ratio control for internal combustion engines. In 2008 American Control Conference (pp. 2058-2063). IEEE.
7. Wang, S. W., Yu, D. L., Gomm, J. B., Page, G. F., \& Douglas, S. S. (2006). Adaptive neural network model based predictive control for air-fuel ratio of SI engines. Engineering Applications of Artificial Intelligence, 19(2), 189-200.

8. He, B., Shen, T., Kako, J., \& Ouyang, M. (2008). Input observer-based individual cylinder air-fuel ratio control: modelling, design and validation. IEEE Transactions on Control Systems Technology, 16(5), 1057-1065.

9. Cavina, N., Corti, E., \& Moro, D. (2010). Closed-loop individual cylinder air-fuel ratio control via UEGO signal spectral analysis. Control Engineering Practice, 18(11), 1295-1306.

10. Recktenwald, G. W., \& Hall, D. E. (2011). Using Arduino as a platform for programming, design and measurement in a freshman engineering course. In Proceedings of the American Society for Engineering Education Annual Conference \& Exposition. June 2011.

11. Barber, R., Horra, M., \& Crespo, J. (2013). Control practices using simulink with arduino as low cost hardware. IFAC Proceedings Volumes 46(17), 250-255.

12. Candelas, F. A., García, G. J., Puente, S., Pomares, J., Jara, C. A., Pérez, J., ... \& Torres, F. (2015). Experiences on using Arduino for laboratory experiments of Automatic Control and Robotics. IFAC-Papers OnLine, 48(29), 105-110.

13. Alsmadi, O. M., Al Jallad, A. A., Abo-Hammoud, Z. S., \& Al Majali, F. J. Arduino-Based Automatic Safety Vehicle Control. In 2nd International Conference on Research in Science, Engineering and Technology (ICRSET'2014), March 21-22, 2014 Dubai (UAE)

14. Kiruthikamani, G., Abinayaa, B., Saranya, B., Devi, P., \& Gayathri, R. (2017). Smart Vehicle Safety System Using Arduino. International Journal of Trend in Research and Development, 3(6), 804-807.

15. Chen, C. L., Chen, T. R., Chiu, S. H., \& Urban, P. L. (2017). Dual robotic arm "production line" mass spectrometry assay guided by multiple Arduino-type microcontrollers. Sensors and Actuators B: Chemical, 239, 608-616.

16. Bonnick, A. (2007). Automotive computer controlled systems. Routledge. Oxford: Butterworth-Heinemann.

17. Najjar, Y. S., Almardini, A. A. W., \& Sawan, A. J. (2019). Comparison of performance using wide-band versus narrow-band oxygen sensors in gasoline engines. Case Studies in Thermal Engineering, 16, 100552.

18. Cappenberg, A. D. (2014). Studi Tentang Berbagai Tipe Bahan Bakar Terhadap Prestasi Mesin Mobil Toyota Xxx. Jurnal Konversi Energi dan Manufaktur UNJ, 1(3), 157-163.

19. Jayanti, N. E., Hakam, M., \& Santiasih, I. (2014). Emisi Gas Carbon Monooksida (Co) Dan Hidrocarbon (Hc) Pada Rekayasa Jumlah Blade Turbo Ventilator Sepeda Motor "Supra X 125 Tahun 2006. Rotasi, 16(2), 1-5. 